\title{
Compulsory Licensing of Technology and the Essential Facilities Doctrine
}

Reiko Aoki* and John Small ${ }^{+}$

August 2003

\begin{abstract}
We consider compulsory licensing of intellectual property as a remedy for anticompetitive practices. We identify aspects of intellectual property that could warrant a different remedy from those developed for access to physical essential facilities. Based on the analysis, we present a characterisation of optimal compulsory licensing for a simple market. We find that royalty payments offer a greater range of choices to a regulator than fixed fees. Thus, even though the marginal cost of supplying access to intellectual property is zero, some unit charging is likely to be efficient.
\end{abstract}

JEL codes: K2, L4

Keywords: essential facilities, intellectual property, access price, royalty, investment

\footnotetext{
* Institute of Economic Research, Hitotsubashi University \& Department of Economics, University of Auckland University. Institute of Economic Research, Hitotsubashi University, Naka 2-1, Kunitachi, Tokyo, 186-8603JAPAN. Ph +81 42580 8344, Fax +81 42580 8333, email: r.aoki@auckland.ac.nz.

+ Department of Economics, University of Auckland. We thank Imelda Maher and Peter Drahos, the conference organisers, for their detailed comments, and are very grateful to John Panzar his valuable insights. Aoki's research is part of the academic Project on Intergenerational Equity (PIE), funded by a scientific grant from Japan's Ministry of Education, Culture, Sports, Science and Technology (grant number 603).
} 


\section{Introduction}

This paper considers economic issues arising at the intersection where utility regulation meets intellectual property. We discuss the relevant features of each, and study the implications of certain unique features of intellectual property for regulatory policy. Our point of departure from the regulatory economics literature is the concept of essential facilities. We argue that some forms of intellectual property are essential facilities and analyze in some detail the similarities and differences between essential facilities and intellectual property.

Within a country, an input or factor of production is regarded as an "essential facility" if two conditions are met. First, there must be no economically viable substitute for the input, so that the owner of the input is able to exercise market power, the impact of which flows through to the output market where consumers incur a welfare loss. Secondly, the market or markets at issue must be sufficiently important for national welfare.

The first leg of this test (economically viable substitution) requires that although it might be physically possible to duplicate the input, the cost of doing so would be too large for any firm to bear. This creates a barrier to entry, behind which the incumbent can extract rents, which will usually create a welfare loss. 
One way to reduce the efficiency loss arising from market power in the final goods market, is for the authority to "declare" the input, by which we mean mandate access to the input by competitors. ${ }^{1}$ This realizes a static efficiency gain - more competition and lower prices - without incurring the cost of duplicating production of the input. However there may be a dynamic cost to achieving that static gain, since a firm considering investment in a genuinely innovative facility could anticipate declaration and decide not to bother investing in the input or innovation. In that case, the rate of innovation will fall and some value enhancing input and final products may never see the light of day. ${ }^{2}$

Intellectual property bestows on its owner the ability to exclude others from using the information or technology. The owner of the intellectual property is able to exercise market power over whatever product requires the patented technology or copyrighted software. Intellectual property is very much like an essential facility in this sense. Indeed, the market power available from all intellectual property and the scale and network economies associated with some forms of intellectual property would seem to place it comfortably within the essential facilities definition. ${ }^{3}$ Instead of treating intellectual property as a type of essential facility and using declaration as remedy, intellectual property laws typically include a different remedy for static inefficiency -

$1 \quad$ "Declare" is the verb used in the A ustralian Trade Practices Act to mean mandate.

This general problem is studied by Armstrong, Doyle and Vickers (1995) among others. For cases in which the downstream market is not contestable as a consequence, see Rey and Tirole (2003).

We refer to databases, trading hubs, and related networks, particularly where complete coverage of a jurisdiction is desirable. 
compulsory licensing. As with declaration, dissipating rents through compulsory licensing will reduce returns from research and development (R\&D) investment which could discourage innovation and create a dynamic loss.

Compulsory licensing is the remedy most often used when the intellectual property owner is abusing market power. ${ }^{4}$ However it is also possible to resort to the essential facilities doctrines to make intellectual property available to other firms or players in the market. This offers an alternative legal route for those seeking changes, which could be particularly attractive when the property at issue is a patent on some chemical entity or basic biological technology necessary for a pharmaceutical product or other form of medical care.

It is important to note that the intellectual property system is explicitly designed to promote innovation. This is quite explicit in the case of patents, which is the intellectual property that our analysis will focus on most closely. ${ }^{5}$ A remedy that reduces the incentive to innovate has precisely the opposite effect. Because intellectual property is essentially information, it has properties that are different from other inputs and goods whose boundaries are defined physically. This suggests that the terms on which

$4 \quad$ The Ergas Committee Report (Commonwealth of Australia, 2000) characterizes compulsory licensing as a remedy for certain breaches of the Trade Practices Act. Fisse (2002) makes a similar point.

5 Analysis for other types of intellectual property, such as copyrights for software, will be discussed where appropriate. 
compulsory licensing is sensibly mandated might differ from the standard access pricing rules used for essential facilities.

In practice there are two reasons for compulsory licensing. The first relates to the technology itself and is most obviously seen in the compulsory licensing of pharmaceutical products. Recent examples are licensing of anti-HIV/ AIDS drugs in South A frica and the anthrax antibiotic ciprofloxacin in Canada. The motivation behind compulsory licensing in these cases seems to be the gain in consumer surplus in the form of saved lives. Lives, not market efficiency, are at stake when the income level is such that monopoly prices for such products are prohibitively expensive for most of the population. The economic concept of dead-weight loss takes on a macabre second meaning in this case.

The second reason for compulsory licensing is to remedy an anti-competitive behaviour, such as foreclosure, in a market for products that rely on the patent. In other words, it seeks to promote competition rather than to address consumer welfare directly. We consider this second type of compulsory licensing. Our interpretation is that this is what the recent Intellectual Property and Competition Review Committee in Australia (henceforth the Committee) was concerned with.

We also focus on those aspects of the role of intellectual property that are unique to smaller countries such as Australia and New Zealand. In 1999, 90\% of Australian patents were granted to non-residents and $87 \%$ of $\mathrm{New}$ Zealand patents were granted to non-residents. Among larger economies, the shares of non-residents among patent 
grantees is much smaller. For the same year, the share of non-resident grantees were $45 \%$ in the U.S.A., $50 \%$ at European Patent Office (EPO) and $11 \%$ in Japan (as shown in Table 1). This suggests that in A ustralia and $\mathrm{N}$ ew Zealand, R\&D investment required to develop the new patented technology is typically not undertaken by domestic firms, unlike the situation in the U.S.A. and other larger economies. Assuming inventors would first patent in their home country, technologies patented in Australia and New Zealand are likely to have already been patented elsewhere. The patent system's roles for promoting innovation and disseminating information are correspondingly less relevant in A ustralia or New Zealand compared with larger economies.

Table 1

Percentage of N on-Resident Filings

for Patents G ranted in 1999

\begin{tabular}{|l|l|}
\hline Country or Entity & Share of N on Residents (\%) \\
\hline Australia & 90 \\
\hline New Zealand & 87 \\
\hline USA & 45 \\
\hline EPO & 50 \\
\hline Japan & 11 \\
\hline
\end{tabular}

Source: WIPO(2002)

The rest of the paper is organised as follows. In the next section we compare "essential facility" and "patented technologies". Comparison of the remedies, "declaration" and "compulsory licensing" follows. We then analyze compulsory licensing as 
recommended the by the Committee. This includes characterisation of socially optimal licensing fees (fixed fee and royalty), and analysis of the effect of the threat of compulsory licensing on innovation. We end with some concluding remarks.

\section{2. "Essential facility" and "patented technology"}

A factor of production is an essential facility when duplication of the input or a close substitute is uneconomical so that the owner or producer of the input is able to extend its power over the input market to another market, namely the output market. In addition, essential facilities must have some significance for the economy as a whole. Possible examples of essential facilities include ports, railroad lines or stations, power transmission and local telecommunications networks. The outputs will be respectively docking services, railway services, electricity retail services, and telecommunication services.

Market power is typically exercised by excluding competitors from the output market, by denying or restricting access to the essential facility, or by structuring access prices to this effect. This has the effect of foreclosing the downstream market in which the essential input is used to supply other (often retail) goods and services. A firm may accomplish this by vertically integrating into the downstream production, using exclusionary contracts with a particular producer, or by charging very high access fees for the facility. 
Intellectual property (IP) is a system for promoting innovation. Starting with a legal definition of the boundary of the property, IP laws allow the owner to appropriate rents by excluding others. The efficient extent and duration of the exclusion is determined with reference to two trade offs. One trade off is static loss against dynamic gain. Static losses arises from the market power conferred through the ability to exclude. This leads to static inefficiency with deadweight loss close to the monopoly deadweight loss. However by allowing the patent owner to temporarily obtain the above normal profits, the presence of an exclusive right makes it worthwhile for someone to commit resources and undertake innovation. This is the dynamic gain. The strength or extent of patent protection will change the balance between the loss and gain.

The other trade off is between the static market inefficiency and the disclosure of information. In return for the right to exclude others, disclosure of the technology is required to obtain a patent. In contrast, if an inventor resorts to trade secrets, she can also exclude others from using the technology without disclosing the information. ${ }^{6}$

If the protected intellectual property is necessary for production of a good, it effectively gives the owner the right to exclude others from producing this good. In the case of patents, the patented technology could cover a production process or input material. In the case of a software copyright, it may be necessary for operating a computer or other $6 \quad$ Not surprisingly, trade secret protection would not allow the owner to exclude everyone - in particular she cannot exclude someone who invents the same technology independently. Since the gain to society from trade secret is small (because there is no information disclosure), the level of market inefficiency that is tolerated should also be small. 
machine or for providing services such as inventory management or accounting. By definition, exact duplication of patented technology or copyrighted software is prohibitively costly, not least because doing so would expose the duplicator to legal action.

Invention of a close substitute (known as "inventing around" the patent) may be physically possible, even patentable or copyrightable. However there are possible infringement litigation costs which must be taken into account in addition to the physical process of inventing the close substitute. Such costs may effectively lead to lack of economically viable substitutes for the technology or the software. Thus, even if physical inventing around appears viable, the intellectual property covering the technology or software may still effectively be an essential facility.

Essential facilities and intellectual property both confer exclusionary power on their owners by virtue of the absence of economically viable close substitutes. ${ }^{7}$ They differ in the reason for the existence of this power however. Patents are by definition a right to exclude others from using the technology. Essential facilities may be such because of

\footnotetext{
$7 \quad$ Strictly speaking, we should differentiate between technology and its market function. A patent may exclude others from using the exact patented technology but there may be other methods of obtaining the same market function. For instance, while there may be several drugs that cure the same diseases, a single patent would protect only one of the drugs. In this case, the patent will not exclude others from providing drugs to cure the disease. There are no market competition issues in this case and our analysis assumes there are not such substitute technologies.
} 
their physical properties (e.g. a port occupying a natural harbour) or by past decisions. Put slightly differently, market power associated with an essential facility arises because of the absence of a specific legal action (declaration) to remove it, whereas market power associated with intellectual property arises because of the presence of a specific legal protection (patenting).

Both require significant capital investment to obtain and thus duplication may be socially very wasteful. This fact is critical in justifying a remedy. This is because with both inputs, once the investment has been sunk and the essential facility built or technology obtained, there is a (gross) gain from giving others access. The gain comes from reducing static dead-weight loss. However if the static gains are too great (for example, if the access price is set too low) there can be adverse dynamic consequences. If duplication were not prohibitively expensive, a more market oriented approach would have less harmful dynamic consequences.

An important difference between physical essential facilities and intellectual property is that the cost of substitutes is outside the control of policy for the former but is endogenous for the latter. Consider a physical essential facility such as a telecommunications network. The cost of duplication or the construction of a close substitute is determined by physical costs, and over time by technological progress, neither of which are within the control of policy makers. In case of patents however, the extent of monopoly power or equivalently the cost of producing a close substitute, can be changed by changing breadth of patent protection. Narrower breadth means more similar technologies fall outside the extent of patent protection. This should make 
"inventing around" using disclosed patent information cheaper. Narrower breadth will also make it more costly for the patent owner to prove infringement which reduces litigation. Narrower breadth will make expected litigation costs lower for the imitator. Thus changing breadth of protection can reduce the cost of close substitutes which may be sufficient to prevent foreclosure. This is a possible remedy for anti-competitive use of patents which is not available for general essential facilities.

There is an alternative to patents for protecting intellectual property: trade secrets. Using this approach involves an attempt to physically prevent access to information. However once someone has independently obtained the information, there is no way to exclude them from using the technology. On the other hand, trade secrets provide no help to those wanting to "invent around" since no information is revealed. In the case of patents, the disclosure required to obtain patent protection can help the invention of close of substitutes. In this sense patents are more socially desirable than trade secrets. If compulsory licensing makes patents less attractive, technologies may be protected by trade secrets. This must be taken into account when considering a remedy.

\subsection{Special features of intellectual property}

Intellectual property has some important features that differentiate it from other goods and factors of production. First of all, use of information is physically non-exclusive. Unlike ports or telecommunications networks, both of which are subject to congestion, it is possible for any number of people or firms to use intellectual property at the same time. In addition, unlike physical assets, once someone has acquired the information, it is impossible for the owner to prevent this person from sharing it with someone else. In 
fact this is why one needs the concept of intellectual property - there are no physical boundaries that define extent of the property.

Another special feature of information is that it will not physically depreciate from use nor will it require maintenance. Thus there is no physical direct cost of using this input. 8 Harbour facilities and telecommunications networks must be run using resources. They also depreciate physically and require resources for their maintenance. The fair access fee needs to cover this cost of using the asset but such reimbursement is not necessary for using intellectual property.

\subsection{Small Country Issues}

In Australia or N ew Zealand, most of the patented technologies were developed abroad (Table 1). As noted above, the purpose of the patent system is to provide incentives for firms to invest in R\&D by granting monopoly rents in return for disclosing the technology. Clearly in Australia and New Zealand these are not the primary functions of a patent however. Technologies patented in these small countries have mostly been invented abroad where firms made their $R \& D$ investment decisions based on profits from larger markets, typically US, EU or Japan. Reducing monopoly rents from Australia or New Zealand may therefore not have such a large cost in lost innovation as it would if the rents being dissipated were those arising from much larger economies.

8 Of course the number of users of intellectual property will change its market value. But this is not a direct cost. 
Similarly, the information disclosure function of the patent system is not very important in smaller economies. Since technologies are usually patented abroad, firms and individuals in Australia and New Zealand can obtain the knowledge from patent disclosure in other countries.

However patenting in a small market is necessary in order for the inventor to appropriate rents from the small market. Since the information is available el sewhere, if the inventor does not obtain a patent, someone else could do so and exclude the inventor from the market. If no one obtains a patent, rents will be dissipated because the technology would be used freely by many. Thus restricting the market power of patent protection in small technology importing countries will lead to static gain, while the dynamic loss from discouraging innovation or less information disclosure would be close to zero.

These international issues do not arise to the same extent with physical essential facilities. The cost of initially constructing major infrastructural assets such as telecommunication networks or railroads, is typically borne domestically. Even if it is not, there is no real prospect of adjusting policy settings such that a greater static gain is obtained without more dynamic loss. This is primarily because such significant additional capital investment is required to extend (say) telephone services into a new country. Consequently, while small and large countries have face similar tradeoffs in respect of physical essential facilities, this is not the case for intellectual property. 


\section{3. "Declaration" and "compulsory licensing"}

In assessing the relevant remedies, we start by characterising the existing system for declaring essential facilities in Australia, then outline the compulsory licensing proposals in that country. This is followed by a comparative analysis that uses a simple economic model.

\subsection{Declaration of essential facility}

Access to essential facilities in Australia involves a process beginning with an application to the National Competition Council to have the service "declared". The Council may recommend declaration of a service if it is satisfied that:

1. access to the service would promote competition;

2. it would be uneconomical for anyone to develop another facility to provide the service;

3. the facility is of national significance;

4. access would not cause undue risk to health or safety;

5. access is not al ready the subject of an effective regime; and

6. access would not be against the public interest.

\subsection{Compulsory licensing of patented technology}


The Review Committee Report (Commonwealth of Australia, 2000) recommends that an order requiring a compulsory license to be made if and only if all of the following conditions are met:

1. access to the patented invention is required for the competition in the (relevant) market;

2. there is a public interest in enhanced competition in that market;

3. reasonable requirements for such access have no been met;

4. the order will have the effect of allowing these reasonable requirement to be better met; and

5. the order will not compromise the legitimate interest of the patent owner, including that owner's right to share in the return society obtains from the owner's invention and to benefit from any successive invention, made within the patent term, that relies on the patent.

Such order should be obtainable on application first to the Australian Competition Tribunal, with rights of appeal to the full Federal Court.

\subsection{Comparison}

Both declaration and compulsory licensing attempt to remedy the existence of an entry barrier that is deterring competition in a market. Both require the establishment of the fact that lack of access to the object (facility or patent) is hindering competition. 
In the case of declaration, a facility is considered an entry barrier when it is not economical to duplicate it. There is no such requirement for compulsory licensing. In this sense the compulsory licensing requirement is more proactive. At the same time, lack of this duplication test could lead to abuse, either in the decision to mandate licensing or the terms on which it was mandated. For instance, as part of a remedy, Microsoft was forced to provide its source code for free (i.e. compulsory licensing with no fee). It seems clear that the lack of a fee was not necessary to have competition in the relevant market, though it is rather less clear whether a duplication test would have changed matters materially in this case.

Compulsory licensing is more explicit about what the patent owner is entitled to when the remedy is used. Recommendation 5 of the Review Committee's report could be interpreted as saying that the patentee should get the monopoly profit with compulsory licensing. This can be from the final product market or from subsequent innovations. However this would contradict the point of this remedy which is to introduce competition. It is impossible for the patent owner to get the monopoly profit while there is competition due to the efficiency effect. ${ }^{9}$

Entitlement for the owner of the essential facility is subsumed in requirement 6 of the declaration condition. In this case, the public interest would be interpreted as being the aggregate interest of consumers and firms. Consumers will gain from competition in the market and the firm that gains access to the essential facility will now have positive profit. The public interest condition means that access to the facility should not erode

\footnotetext{
$9 \quad$ See discussion of the economics of compulsory licensing (section 3.5) for exceptions.
} 
the facility owner's profit so much that a rational firm will never investment in the essential facility. If there were no telecommunication network, consumers would be very much worse-off.

\subsection{Economics of declaring and essential facilities}

The fact that incumbent invested in the facility means that $\pi^{M}-f>0$, where $\pi^{M}$ is the monopoly profit and $f$ is the cost of the facility. The fact that duplication is uneconomical and that it is an entry barrier means that

$$
\pi^{\mathrm{D}}-\mathrm{f}<0
$$

where $\pi^{\mathrm{D}}$ is the duopoly profit. This occurs because $\pi^{\mathrm{M}}>\pi^{\mathrm{D}}$, so the duopoly profit is less than the monopoly profit. (In fact, usually the efficiency effect $\pi^{\mathrm{M}}>2 \pi^{\mathrm{D}}$ holds, in which case competition reduces the aggregate profit achievable from the market.) This is a critical condition.

If market efficiency can be achieved in some other way, there is never an incentive to duplicate the essential facility, and $W D-2 f<W D-f$, where $W D$ is the duopoly social surplus. In fact this inequality is true for any social surplus.

There is always some social benefit from competition, so that $W^{M}-f<W^{D}-f$, where WM is the monopoly social surplus. These benefits provide incentive for a facility to be always declared. However if the incumbent's profit were really reduced to $\pi^{\mathrm{D}}$ after declaration and the incumbent rationally anticipated such action, condition (1) means 
the investment would have never taken place. One can interpret requirement 6 of the declaration conditions "access would not be against the public interest" as addressing this problem by ensuring that the incumbent's profit after declaration should be sufficiently large so that the initial investments would take place.

It should be noted that there are situations where duplication may be socially beneficial: $W M-f<W D-2 f$.

This occurs when the consumer surplus gain from competition is very large so that WM WD - WM is very large, specifically greater than $f$. However, a large consumer surplus due to a very competitive market is very likely to also imply a small duopoly profit, resulting in condition (1) being satisfied. In that case, even though duplication is socially desirable, there is no private incentive to do so. In principle, the incentive could be restored without declaration, by increasing the profit of the entrant until it is greater than $\mathrm{f}$. Possible methods include transferring profit from the incumbent or subsidising the entrant, though the latter may lead to additional inefficiency.

\subsection{Economics of "compulsory licensing"}

The fact that a patentee undertook the innovation means that $\pi^{\mathrm{M}}-\mathrm{k}>0$, where $\mathrm{k}$ is the $R \& D$ investment. The fact that a patent is an entry barrier means that

$$
\pi^{\mathrm{D}}-\mathrm{k}<0
$$


As in the case of the essential facility, there is always social benefit from avoiding duplication of the invention, $W^{D}-2 k<W^{D}-k$, and from competition, $W^{M}-k<W^{M}-k$.

This would result in the same problem of no investment as in the essential facilities case if licensing resulted in duopoly profit for the patent owner since (2) holds. However recommendation 5 "the order will not compromise the legitimate interest of the patent owner" avoids this problem by guaranteeing profit close to $\pi^{\mathrm{M}}$ to the patentee. It cannot be $\pi^{\mathrm{M}}$ itself however, since then there will be no profit left for the licensee. ${ }^{10}$

\subsection{Issues Unique to A ustralia and N ew Zealand}

For technologies that are developed abroad, the need to guarantee a profit to make R\&D incentive compatible would not be an issue. The patentee (typically holding patents in other countries and markets for the same technology) would patent in Australia or New Zealand as long as expected profit were positive. This would support licensing agreements that violate requirement 5 . That is, compulsory licensing would be socially desirable and the foreign technology owner will still patent in Australia or N ew Zealand because otherwise it will obtain no profit at all from these markets.

\subsection{When is compulsory licensing unnecessary?}

\footnotetext{
10 There are exceptions to this, such as: (1) If the patentee practiced uniform pricing but if the licensee were able price discriminate; (2) If licensee were able to produce more efficiently than the patentee.
} 
Patent licensing sometimes occurs under non compulsory circumstances and such situations should be excluded from any licensing regime. For example, a patent owner may license when she is unable to implement the technology herself, perhaps because she does not own a suitable production facility which would be case for universities or individual inventors. In this case, voluntary licensing allows the patent owner to obtain the resources to implement the patent.

A nother case in which voluntary licensing would occur is where there is a firm that has lower marginal cost than the patentee. This would particularly make sense if the demand is so large relative to patentee's cost curve that she would be forced to produce in a region where marginal costs increase. There will be benefit from splitting production by licensing to another firm. Thus compulsory license would be necessary only when the patentee has no cost disadvantage.

An important case where only compulsory licensing occurs is when the patent covers an intermediate technology. A technology is an intermediate technology when it is result of basic research and requires more research or development research before it becomes a final product (A oki and Nagaoka 2002). Patents that cover gene sequencing or new chemical compound are such examples. Other sequences might be necessary or it may be that determining the effect of the gene sequence requires more research and there is no immediate product that uses this patent. Similarly, in order for a new chemical compound to become a useful drug, its efficacy and safety may still need to be determined. 
When more risky investment is required until there is a useful product, it may be socially desirable to have many firms engaging in the next innovative step. Because this approach involves some duplication of effort it is not necessarily cost effective. However there may well be situations in which the patent owner would like to be the sole developer of the final product but society would be better off if this were not the case.

\section{Compulsory licensing}

In the case of physical essential facilities such as a telecommunication network or port, the access fee must cover at least the direct cost of using the asset. U se of the facility can be measured in units and there is a direct cost associated with each unit. Thus, the access fee takes form of a per unit fee, i.e., a price.

An intellectual property is either used or not. There is no concept of "units" of technology.11 When a person uses a patented technology or copyrighted software, this will not prevent anyone else from using it at the same time nor will it depreciate the quality of the information. Thus there is no direct cost of using information. Moreover, the lack of units means there is no natural way of defining price or the marginal cost of using information. Fortunately it is impossible to over use information and there is really no need for marginal cost.

11 There may be an issue of how many patents or how many items of copyrighted software, but each unit is a separate patent or software, rather than more units of the same thing. 
Therefore, apart from the dynamic (investment) issues, the terms on which intellectual property is licensed only has efficiency consequences on the output market. Efficient use of information, in contrast to an efficient use of network, is not an issue. Thus, the access fee for intellectual property can be a one time fixed fee or price per unit of output, i.e., a royalty. 12

\subsection{Fixed fee versus royalty}

We employ a very simple model of two firms engaged in production of a homogeneous good. The patent covers a process innovation technology. Using the patented technology reduces the marginal cost of production of the final good from co (old marginal cost) to $c_{N}$, where $c_{N}<c_{0}$. The demand function for the output is assumed to have the linear form: $p=a-q$, where $p$ is the price and $q$ is total output. We denote the patent owner by $\mathrm{P}$ and the licensee by $\mathrm{L}$. Prior to compulsory license, $\mathrm{P}$ is the incumbent, the sole producer of the final product and $L$ is the potential entrant unable to enter because it has no access to the patented technology. We assume firms engage in Cournot competition.13

12 There may also be combination of these two elements, but we will not consider these options here. Note however, that a combination of fixed fee and price, i.e., two part tariff, will always do strictly better than using only one of the two.

13 By Cournot competiton we mean an oligopoly where the product is homogeneous and firms decide on outputs simultaneously. The equilibrium price is determined by the market so that demand will be equal to the total outputs supplied. In equilibrium each firm's output and profit is decreasing in its own marginal cost (lower cost, higher output and profit) and increasing 


\section{Patented technology is a barrier to entry}

Higher cost of production does not prevent entry per se The cost difference must be sufficiently large so that $L$ would not be able to enter the market if it produces with the old technology and so incurs the old marginal cost co. Given that it is Cournot competition, this occurs if

$$
\mathrm{c}_{\mathrm{O}} \geq \frac{\mathrm{a}-\mathrm{c}_{\mathrm{N}}}{2}
$$

Entry will be blockaded when this condition holds. In this case, P is the sole producer and it collects monopoly profit,

$$
\pi^{\mathrm{M}}=\left(\frac{\mathrm{a}-\mathrm{c}_{\mathrm{N}}}{2}\right)^{2}
$$

Compulsory licensing will give $L$ access to the patented technology and its marginal cost will also be $c_{N}$. Although there was a case where a U.S. Court ordered compulsory licensing with zero fee ${ }^{14}$, usually the patent owner is guaranteed some compensation

in the rivals' marginal costs (lower cost, lower and profit). See for example, Aoki and Tauman (2001) for the exact formulation.

14 Dell Corporation VL Bus Patents, 1997. 
with compulsory licensing. We denote by $v$ the minimum total profit (profit from sales of output plus licensing fee) of $P$.

\section{Fixed access fee}

The fixed fee $F$ must be paid from $L$ to $P$. Both firms have marginal cost $C_{N}$. Profit from sales of the output for each firm is the Cournot profit with symmetric costs,

$$
\pi^{\mathrm{C}}=\left(\frac{\mathrm{a}-\mathrm{c}_{\mathrm{N}}}{3}\right)^{2}
$$

The net profits given the licensing payment $F$ are $\pi_{\mathrm{P}} \mathrm{F}=\pi^{\mathrm{C}}+\mathrm{F}$; and $\pi_{\mathrm{L}}^{\mathrm{F}}=\pi^{\mathrm{C}}-\mathrm{F}$. Total output is,

$$
\mathrm{Q}^{\mathrm{F}}=\frac{2\left(\mathrm{a}-\mathrm{c}_{\mathrm{N}}\right)}{3}
$$

The greater is the output, the greater the social surplus and smaller the deadweight loss. An attractive property of the fixed fee is that it does not affect the marginal profit and output decisions of the firms. Rather, it is a pure transfer from licensee to patent owner which does not effect decisions at the margin of production. 
We can identify conditions that F must satisfy for it to be feasible. $L$ should not make a loss, so F must satisfy

$$
\pi_{\mathrm{L}} \mathrm{F} \geq 0 \quad \Leftrightarrow \quad \mathrm{F} \leq \pi^{\mathrm{C}}
$$

Further, if $\mathrm{P}$ must be guaranteed $\mathrm{v}$, then

$$
\pi_{\mathrm{P}} \mathrm{F} \geq \mathrm{V} \quad \Leftrightarrow \quad \mathrm{F} \geq \mathrm{V}-\pi^{\mathrm{C}}
$$

Any $\mathrm{F}$ that satisfies these two equations is optimal. There will no difference in the size of the social surplus among the feasible fees $F$. The maximum possible $\pi_{\mathrm{P}} \mathrm{F}$ is $2 \pi^{\mathrm{C}}$ which is less than the monopoly profit $\pi^{\mathrm{M}}$ due to the efficiency effect.

\section{Proposition 1}

With fixed feelicensing, the final good market will be a Cournot oligopoly with identical marginal costs, $c_{N}$. The sum of profits will always be $2 \pi^{c}$ for any incentive compatible $F$. The fixed fee determines how this is allocated between patent owner and licensee. With a positive fee, patent owner gets more than Cournot equilibrium profit and licensee gets less. With zero fee, both get exactly the Cournot equilibrium profit.

\section{Royalty access fee}

$\mathrm{L}$ will pay $\mathrm{P}$ a royalty of $\mathrm{r}$ per unit of output produced using the patented technology. This means L's marginal cost is effectively $c_{N}+r$. The market will again be a Cournot oligopoly, but with asymmetric marginal costs, $c_{N}$ and $c_{N}+r$. The equilibrium outputs are 


$$
q_{P}=\frac{a-2 c_{N}+\left(c_{N}+r\right)}{3} \quad, \quad q_{L}=\frac{a-2\left(c_{N}+r\right)+c_{N}}{3} .
$$

The equilibrium profits will be

$$
\pi_{P}^{r}=\left(\frac{a-2 c_{N}+\left(c_{N}+r\right)}{3}\right)^{2}+r q_{L} \quad, \quad \pi_{L}^{r}=\left(\frac{a-2\left(c_{N}+r\right)+c_{N}}{3}\right)^{2} .
$$

P's profit is concave in $r$ and is maximised at $r=\left(a-c_{N}\right) / 2$. When $r=0$, profit is the Cournot equilibrium profit with symmetric marginal costs, $\pi^{\mathrm{C}}$. The maximum is the monopoly profit, $\pi^{M}$. When the royalty is $r=\left(a-C_{N}\right) / 2$, L's marginal cost is effectively $c_{N}+r=\left(a+c_{N}\right) / 2$ meaning with this marginal cost, condition (3) holds with equality if we substitute $c_{O}=c_{N}+r$. This is such a high royalty fee that it increases $L$ 's effective cost to a level where it is indifferent between producing (for zero profit) and not producing.

Total output is

$$
\mathrm{Q}^{\mathrm{r}}=\frac{2 \mathrm{a}-2 \mathrm{c}_{\mathrm{N}}-\mathrm{r}}{3}
$$

which is decreasing in $r$. Higher $r$ effectively increases marginal cost for $L$, who produces less in equilibrium as result. Although $\mathrm{P}$ produces more, the total output decreases. Unlike the case of fixed fees, a royalty effects marginal profitability and thus 
the equilibrium outputs. The socially optimal royalty, $r *$ is the smallest $r$ that satisfies $\pi_{\mathrm{P}}^{\mathrm{r}} \geq \mathrm{v}$

\section{Proposition 2}

With royalty licensing, there is an optimal royalty $r^{*}$. At this level, the patent owner's profit is exactly the minimum level, $v$, while the licensee's profit will be strictly less than $\pi^{\mathrm{C}}$. With zero royalty, the market will be a Cournot equilibrium with symmetric costs, $C_{N}$. Each firm gets the Cournot equilibrium profit. Note that with the royalty, it is possible for $\pi_{\mathrm{P}}^{\mathrm{r}}$ to be greater than $2 \pi^{\mathrm{c}}$.

\subsection{Effect of threat of compulsory licensing}

Let $\left(\pi_{\mathrm{P}}, \pi_{\mathrm{L}}\right)$ be the profit allocations of the patent owner and the potential rival, respectively.

If there is no system of compulsory licensing, $\pi_{P}=\pi^{M}$ and $\pi_{L}=0$. The patent owner has no incentive to share the technology and will be a monopolist in the product market.

If compulsory licensing is implemented, then net profits would be

$$
\overline{\pi_{P}}=\pi_{D}(1+\alpha) \quad, \overline{\pi_{L}}=\pi_{D}(1-\alpha)
$$


where $\alpha$ is the share of profit that licensee pays to the patent owner. Even if the compulsory licensing is not actually implemented, the possibility of compulsory licensing changes the bargaining positions of patentee and the potential licensee.

Specifically, if we denote by $\pi^{A}$ the sum of profits that two firms can achieve, we can define a N ash Bargaining Game with feasible set

$$
\left\{\left(\pi_{\mathrm{P}}, \pi_{\mathrm{L}}\right) \mid \pi_{\mathrm{P}} \geq 0, \pi_{\mathrm{L}} \geq 0, \pi_{\mathrm{P}}+\pi_{\mathrm{L}} \leq \pi^{\mathrm{A}}\right\}
$$

and disagreement point $\left(\overline{\pi_{\mathrm{P}}}, \overline{\pi_{\mathrm{L}}}\right)$. The N ash Bargaining Solution al location is then,

$$
\pi_{\mathrm{P}}^{\mathrm{NBS}}=\frac{1}{2} \pi^{\mathrm{A}}+\alpha \pi^{\mathrm{D}} \quad ; \quad \pi_{\mathrm{L}}^{\mathrm{NBS}}=\frac{1}{2} \pi^{\mathrm{A}}-\alpha \pi^{\mathrm{D}} .
$$

Since $\pi^{\mathrm{A}} \leq \pi^{\mathrm{M}}$, this shows that the patentee is worse-off with the possibility of compulsory licensing.

If $\pi^{\mathrm{A}} \geq 2 \pi^{\mathrm{D}}$, the (potential) licensee is better-off with the possibility of compulsory licensing. Note that this is true for any $\pi^{\mathrm{A}}$ such that $2 \pi^{\mathrm{D}} \leq \pi^{\mathrm{A}} \leq \pi^{\mathrm{M}}$. Firms will be strictly worse-off or better-off when the inequalities are strict. If the patentee is a foreign firm and licensee is a domestic firm, the domestic firm will always support compulsory licensing. This is independent of if the resulting product market is more competitive or not. That is, even if $\pi^{\mathrm{A}}=\pi^{\mathrm{M}}$. 
The threat of compulsory licensing will al ways make the patentee worse off. This means there will be innovations that would not be undertaken as result of threat of compulsory licensing that would have been undertaken otherwise.

\section{Concluding Remarks}

This paper has examined the similarities and differences between intellectual and physical property in the context of the essential facilities doctrine. It seems apparent that some forms of intellectual property could meet the basic criteria for an essential facility, in being uneconomic to duplicate and having national economic significance. Given this motivation, we examined the economic properties of intellectual property to develop insight as to the appropriate terms of mandated third-party access.

Intellectual property is a information good with properties that differ significantly from other goods. Most importantly, information goods are not congestable, and do not wear out with use. These features motivate the use of alternative remedies for situations in which third party access is in the social interest but not in the private interest of the property owner. Compulsory licensing is the remedy which has evolved, but this is a relatively recent development and the appropriate terms of such licensing have not yet been subject to detailed economic analysis. It seems likely that the special nature of 
information goods might require licensing fee structures that differ from those used for access pricing for declared essential facilities.

Our analysis turns on the fact that there is no marginal cost for the use of information goods. This implies suggests that efficient use of existing information is not an issue, and that only efficiency in the final good market needs to be considered. We compared two possible pricing regimes: fixed fees and royalty payments, and found that royalty payments allow greater choice among profits and consumer welfare in the final good market. We conjecture that this flexibility could be further increased through the use of a combination of fixed fees and royalties.

The fact that royalties are preferred to fixed fees is interesting for at least three reasons. Firstly, this approach connects the facility owner's return to the marginal value it provides rather than the marginal cost of doing so. This contrasts with the situation in respect of access to physical essential facilities, which is most frequently cost-based. Secondly, it explicitly violates the standard economic prescription for efficiency which involves setting prices at marginal cost where possible. In the case of compulsory licensing of intellectual property, the marginal cost of usage is generally zero. Finally, this theoretical finding also seems consistent with recent decisions in compulsory licensing cases, where zero marginal fees are a rarity.

We also found that there are close similarities between the dynamic effects of compulsory licensing of intellectual property and mandating third party access to physical essential facilities. Using the Nash Bargaining approach, we showed that 
independent of exactly what the licensing method is, the mere possibility of compulsory licensing can lead to loss in dynamic efficiency. This effect implies that the threshold tests for compulsory licensing should be sufficiently high to ensure that the resulting static gains are large enough to outweigh such dynamic losses. 


\section{References}

Aoki, R. and S. Nagaoka, 2002, The Utility Standard and the Patentability of Basic Research, Center for International Research on the Japanese Economy Discussion Paper Series F-160, University of Tokyo.

Aoki, R. and Y. Tauman, 2001, Patent Licensing with Spillovers, Economics Letters 73, 125-130.

Armstrong, M., C. Doyle, and J. Vickers, 1995, The Access Pricing Problem: A Synthesis, Journal of Industrial Organization 44(2), 131-150.

Commonwealth of Australia, 2000, Review of Intellectual Property Legislation under the Competition Principles Agreement - Final Report by the Intellectual Property and Competition Review Committee.

Consumer Project on Technology, 2001, Talking Points on Cipro Patent Dispute, www.cptech.org/ ip/ health/ cl/ cipro/ talkingpoints.html

Ergas, H., 2002, Treatment of Unilateral Refusals to License and Compulsory licensing in Australia, presented at U.S. Federal Trade Commission Hearing on Competition and Intellectual Property Law and Policy in the Knowledge-Based Economy, Session on 
Refusals To License and Compulsory Licensing in the European Union, Canada, and Australia, www.ftc.gov/ opp/ intellect/ 020523ergasdoc.pdf

Fisse, B., 2002, Intellectual Property Rights and Competition Law - The Government's Response to the Ergas Committee:'s Recommendation on Section 51(3), Information Economics and Policy, this edition.

Rey, P. and J. Tirole, 2003, A Primer on Foreclosure, forthcoming Handbook of Industrial Organization III.

WIPO, 2002, WIPO Industrial Property Statistics Publication B 1999, Part I: Extracts, www.wipo.org/ ipstats/ en/ publications/ b/ 1999/ pubb-i.htm 